Germany, states that the primary waves arrived at $4^{\mathrm{h}} 38^{\mathrm{m}} 55^{\mathrm{s}}$, and the secondary waves at $4^{\mathrm{h}} 47^{\mathrm{m}} 54^{\mathrm{s}}$, giving the distance of the epicentre from Hamburg at $7,600 \mathrm{~km}$. As the region of the supposed epicentre is sparsely populated, it will be some while before direct information is available.

\section{The Science Museum: Recent Acquisitions}

A LARGE collection of astrolabes, portable sundials, clocks and other scientific instruments, mainly of the sixteenth and seventeenth centuries, has been presented to the Science Museum by Mr. W. E. Miller and has now been placed on exhibition. The astrolabes are particularly fine examples; they include a fifteenth-century specimen from Germany and a sixteenth-century Flemish instrument, probably by Arsenius, one of the leading makers of his era. Among the sundials are several unusually large and fine ivory tablet dials by well-known south German makers of the early seventeenth century, as well as an interesting series of pocket dials of various types, many of them indicating time on the old Italian system in which the day-and-night period was divided into twenty-four equal hours, starting from zero at sunset and counting from 1 up to 24 . The clocks have small projections opposite the hour numbers on the dial, so that the time can be found by touch during the night.

\section{The Night Sky in September}

THE sun crosses the celestial equator at the autumnal equinox (or First Point of Libra) on September 23 at $17^{\mathrm{h}}$ U.T. The moon is full on September 9 at $20 \cdot 1^{\mathrm{h}}$ and new on September 23 at $20 \cdot 6^{\mathrm{h}}$. For a few days near full phase, the moon rises only 21-23 minutes later on successive evenings instead of the normal 50 minutes in these latitudes-hence the Harvest Moon. The moon occults two naked-eye stars during the month, namely: (1) $\delta$ Piscium (mag. 4.6) on September 11, when its reappearance from behind the moon's disk, as seen from Greenwich, takes place at $22^{\mathrm{h}} 40 \cdot 6^{\mathrm{m}}$ U.T. at position angle $238^{\circ}$ from the north point; (2) $\varepsilon$ Tauri (mag. 3.6) on September 15, the disappearance taking place at $22^{\mathrm{h}} 32 \cdot 2^{\mathrm{m}}$ at $131^{\circ}$ and the reappearance at $23^{\mathrm{h}} 07 \cdot 5^{\mathrm{n}}$ at $211^{\circ}$. The respective times and position angles as seen from Edinburgh are $22^{\mathrm{h}} 35 \cdot 4^{\mathrm{m}}\left(118^{\circ}\right)$ and $23^{\mathrm{h}} 18 \cdot 9^{\mathrm{m}}$ $\left(224^{\circ}\right)$. Lunar conjunctions with the planets occur as follows: with Jupiter on September 8 at $7^{\text {h }}$; with Saturn on September 12 at $8^{\mathrm{h}}$; with Mars on September 22 at $14^{\text {h }}$ and with Venus on September 27 at $9 \mathrm{~h}$. Mars, a morning star difficult to see, is in conjunction with Mercury on September 4 at $20^{\mathrm{h}}$ and September 16 at $15^{\mathrm{h}}$; on September 5, Mars is near the first magnitude star Regulus. Jupiter is a bright object rather low in the night sky and southing at about $22^{\mathrm{h}}$ in mid-September. The various phenomena of the satellites may be followed with the aid of the tables and diagram given on pp. 616-617 of the Nautical Almanac for 1938. The four bright inner satellites, visible with binoculars, are most closely grouped near the planet at $22^{\mathrm{h}} 15^{\mathrm{m}}$ on September 1 , 7 (all eastwards), 8, 10 (one satellite occulted), 17 (the same satellite again occulted by Jupiter), 18,
25 and 26. Saturn, which is now visible throughout the night, souths at about $1^{\mathrm{h}} 30^{\mathrm{m}}$ in the middle of the month. The diameter of the minor axis of the ring system is about $8^{\prime \prime}$. At $22^{\text {h }}$ on September 15 , Arcturus is setting in the north-west; Aldebaran is rising in the north-east, preceded by the beautiful cluster of the Pleiades.

\section{Announcements}

Mr. R. W. Hammton has been appointed to succeed Mr. E. T. Richmond as director of the Palestine Department of Antiquities. Mr. Hamilton has been acting director since the retirement of Mr. Richmond a year ago, and joined the staff of the Department as inspector in 1931 after experience with the British School of Archæology in Palestine.

IN NATURE of May 7, p. 823, concern was expressed over the geophysical observatory at Zi-Ka-Wei. A correspondent informs us that he has just received a parcel of seismograms from the observatory. Thus in spite of the troubled times around Shanghai, the observatory is apparently carrying on its work.

THE Rockefeller Foundation has offered and the London County Council has accepted the sum of $£ 2,500$ for the assistance of psychiatric research at the Maudsley Hospital.

THE twenty-fifth French Congress of Medicine will be held at Marseilles under the presidency of Prof. Olmer on September 26-28. Further information can be obtained from Prof. Roger, 66 Boulevard Notre-Dame, Marseilles.

The second International Spa Federation Congress will be held in Berlin during the second half of September and will consist of five sections devoted respectively to the economic, legal, medical, and technical aspects, and tourism and propaganda. Further information can be obtained from Reichsfremdenverkehrsbund, Potzdamer Platz 1, Berlin.

WE have received a copy of "Spectrochemical Abstracts, 1933-1937", by F. Twyman (London : Adam Hilger, Ltd., 3s. I0d., including postage $4 s$.). This is a 52-page bibliography with abstracts of 228 papers on spectro-chemical analysis which have appeared in the period stated. The references to the literature are grouped in an author index, to which references are made in the subject-matter, which is conveniently divided into topies under materials. There is also a list of recent books on the subject. The work, which is bound in limp covers, will be welcomed in scientific and technical laboratories.

REFERRING to the letter by E. V. Newnham entitled "Effects of Floods in East Norfolk", published in NATURE of August 6, p. 257, Dr. Margaret Jepps writes: "Late in July one still passed (at Horsey, Norfolk) suddenly from a green landscape in high summer dress to a wintry scene with bare hedges and leafless woods between the brown wastes where in places the frost yet appeared to lie, since there had been too little rain to wash away the salt left by the receding seas." 